\title{
Nationwide outbreak of Salmonella enterica serotype 4,[5],12:i:- infection associated with consumption of dried pork sausage, France, November to December 2011
}

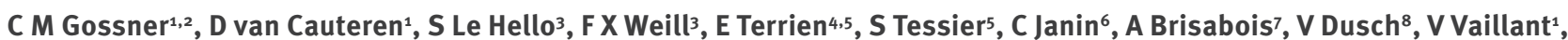
N Jourdan-da Silva (n.jourdan@invs.sante.fr) ${ }^{1}$

1. Institut de Veille Sanitaire (InVS), Saint-Maurice, France

2. European Centre for Disease Prevention and Control (ECDC), Stockholm, Sweden

3. Institut Pasteur, National Reference centre for Salmonella, Paris, France

4. Programme de formation à l'épidémiologie de terrain (PROFET), Institut de Veille Sanitaire (InVS), Saint-Maurice, France

5. Cellule de l'InVS en régions (Cire) Bourgogne Franche-Comté, France

6. Cellule de l'InVS en régions (Cire) Lorraine-Alsace, France

7. Anses, Laboratoire de Sécurité des Aliments, Maisons Alfort, France

8. Direction générale de l'alimentation, Mission des urgences sanitaires, Paris, France

Gossner CM, van Cauteren D, Le Hello S, Weill FX, Terrien E, Tessier S, Janin C, Brisabois A, Dusch V, Vaillant V, Jourdan-da Silva N. Nationwide outbreak of Salmonella enterica serotype 4,[5],12:i:- infection associated with consumption of dried pork sausage, France, November to December 2011.

Euro Surveill. 2012;17(5):pii=20071. Available online: http://www.eurosurveillance.org/ViewArticle.aspx?Articleld=20071

An outbreak of the monophasic variant of Salmonella enterica serotype 4,[5],12:i:- occurred in November and December 2011 in France. Epidemiological investigation and food investigation with the help of supermarket loyalty cards suggested dried pork sausage from one producer as the most likely source of the outbreak. Despite the absence of positive food samples, control measures including withdrawal and recall were implemented.

\section{Outbreak description}

On 7 December 2011, the National Reference Centre for Salmonella (NRC) alerted the French Public Health Institute (InVS) about a two-fold increase of Salmonella enterica serotype 4,[5],12:i:- since the first week of November. Between 31 October and 18 December (week 44 to week 50), a total of 337 cases were identified (Figure 1). The median age was 10 years (range: 0-90 years) with about $30 \%$ of children under five. A majority of women were affected (female to male sex ratio: 1.22). Cases were reported throughout France (Figure 2).

An epidemic of Salmonella enterica 4,[5],12:i:- was already observed about three months prior to this outbreak. Between 1 August and 9 October, 682 cases were reported (Figure 1), of whom 100 cases were interviewed at the time but no common vehicle of infection could be identified. In comparison, 212 cases with this serotype had been isolated during the same period in 2010.

These two consecutive outbreaks appeared in a context of emergence of monophasic variants of Salmonella
Typhimurium all over Europe in humans, animals and food products $[1,2]$. Surveillance data from the French Agency for Food, Environmental and Occupational Health and Safety (Anses), showed that this 4,[5],12:i:variant had been identified in multiple animal and food samples including pork and beef [3]. While this serotype was rarely identified before the mid-1990s, it is now among the most reported Salmonella serotype in the European Union [2,4-7, and personal communication, European Centre for Disease prevention and Control, 17 Jan 2011]. In France, serotype 4,[5],12:i:ranks third among strains isolated from the pork industry (pork carcasses, pork meat and processed pork meat products ("charcuterie") in 2011.

An outbreak investigation team composed of experts from the InVS, NRC, Anses and the French Directorate General for Food (DGAL) was set up and launched simultaneously epidemiological, microbiological and food investigations to define the extend of the outbreak and identify the vehicle of transmission.

\section{Epidemiological and \\ microbiological investigations}

Epidemiological investigation

A case was defined as a person resident in France, who had clinical sign of Salmonella infection and for whom monophasic Salmonella enterica serotype 4,[5],12:i:was isolated from blood, stool or urine samples after week 44, i.e from 31 October to 18 December 2011 and received at the NRC.

In the defined period, 337 cases were identified. We interviewed 90 cases (or the parents for the children) 
by telephone with a standardised semi-structured questionnaire. The interviews were conducted between 7 and 21 December 2011. Date of onset of these cases ranged from 25 September (week 38) to 8 December (week 49). The first 62 cases were interviewed with a trawling questionnaire covering travel history, contact with other diarrhoea cases and food consumption during the seven days prior to symptoms onset. From 14 December onwards, interviews of the 28 most recent cases were undertaken with a lighter version of the questionnaire focusing on consumption and place of purchase of pork delicatessen.

During the interviews of the first 62 cases, 53 cases (84\%) reported eating cooked ham, 45 cases (73\%) Emmental cheese, 42 cases (68\%) dried pork sausages, 42 cases $(68 \%)$ chicken, 38 cases $(60 \%)$ minced beef and 38 cases (60\%) eggs. Dried pork sausages were the only food item that appeared to have been consumed more frequently than expected. We compared this proportion with the consumption of controls who were interviewed during a case control study on the risk factors for Campylobacter infection: $46 \%$ of the controls had consumed such products (week 44 to 51 , $\left.n=53, p<10^{-3}[8]\right)$.

In total, 87 of 90 of the cases reported eating pork delicatessen and the most common items consumed were cooked ham (74 cases, $82 \%$ ) and dried pork sausage (58 cases, 65\%). In addition, 42 interviewed cases (47\%) reported buying pork delicatessen at supermarket chain A, and 18 cases (22\%), 16 cases (18\%), and $14(16 \%)$ at supermarket chain $B, C$ and $D$, respectively. These results are not exclusive as about $33 \%$ of the supermarket chain B's clients are also clients of supermarket chain $\mathrm{A}$.

Health authorities of the European Union were first alerted on the 9 December and regularly updated through the Epidemic Intelligence Information System (EPIS) and the Early Warning Response System (EWRS) of the European Centre of Disease Prevention and Control (ECDC). As of 16 January 2012, no other European country has reported an excess of Salmonella enterica serotype 4,[5],12:i:- in November and December 2011.

\section{Microbiological investigation}

The NRC performed subtyping on a selection of 129 monophasic variants with serotype 4,[5],12:i:- isolated from cases between 2 November and 5 December 2011.

PulseNet-standardised Xbal pulsed-field gel electrophoresis (PFGE) [9] multilocus variable number of tandem repeats analysis (MLVA) subtyping [10] and molecular typing based on the CRISPR polymorphisms (Crispol subtyping) [11] revealed a major profile among the epidemic isolates. It was characterised by a XTYM159 PFGE pattern (found on 12 of 13 tested strains), a 3-13-9-NA-211 MLVA profile (9 of 9 tested strains) and a Crispol type 1 (87 of 129 tested strains). The antibiotic resistance ASSulTe (resistance to ampicillin, streptomycin, sulphonamide and tetracycline) was found on all 33 tested strains. Those profiles are currently predominant in France, and it was therefore not possible to distinguish with certainty between epidemic and non-epidemic cases.

\section{FIGURE 1}

Salmonella enterica 4,[5],12:i:- cases reported by the National Reference Centre, by week of isolation at the primary laboratory, France, $2011(\mathrm{n}=1,721)$

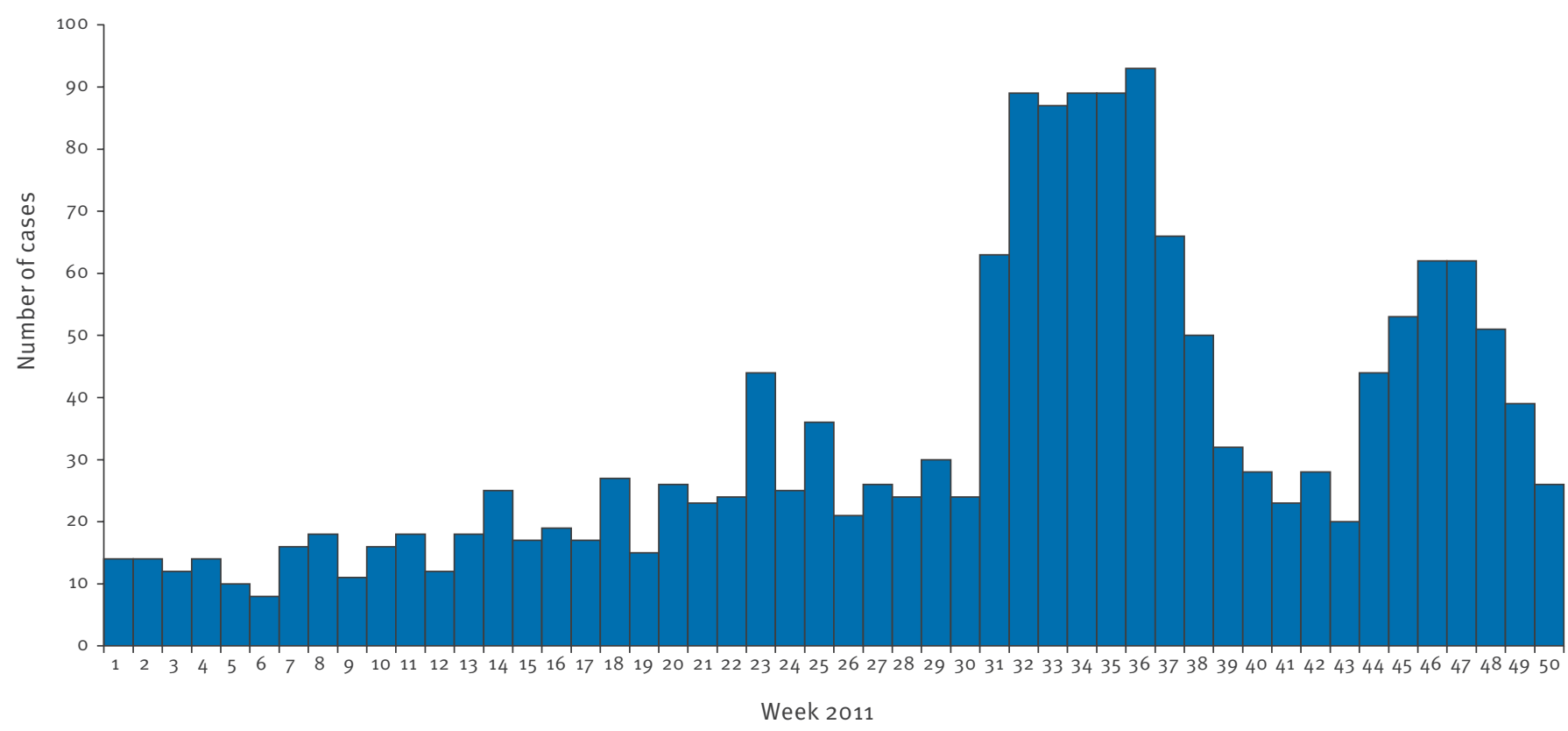


Food investigation and trace-back

\section{Loyalty cards}

Epidemiological investigations pointed to a dried pork sausage purchased principally at supermarket chain $A$ and consumed after week 44 2011. Therefore purchases of pork delicatessen at supermarkets $A$ and $B$ up to four weeks prior to symptom onset were investigated by the DGAL using data recorded through supermarket loyalty cards.

Among the 90 interviewed cases, 39 provided the number of their loyalty card for supermarket chain A during the interview. For 17 cases no purchases of dried pork sausage could be found. Of the 22 cases with documented purchase of dried pork sausage, 15 had bought sausage from a French producer $\mathrm{X}$ and the remaining seven cases bought sausages of seven different brands and origins from other producers. Dried pork sausages from producer $X$ represented less than $3 \%$ of supermarket chain A's sales for this type of food item.

Eleven loyalty cards from supermarket chain B were collected. However, the supermarkets of chain B buy products individually rather than centrally for the whole chain, and the products are therefore not coded in the central database and cannot be traced through the loyalty card data.

\section{Investigation at producer $\mathrm{X}$}

Forty-five lots of the pork sausage (one lot $=8,000$ sausages) had been produced between 1 September and 15 December 2011. Between 1 October and 15 December, 80 to $100 \%$ of the sausages were distributed to supermarket chain A. The remaining lots were distributed to

\section{FIGURE 2}

Incidence rate, per 100,000 inhabitants and per region, of Salmonella enterica 4,[5],12:i:- cases isolated by the National Reference Centre, 31 October to 18 December 2011 , France $(n=337)$

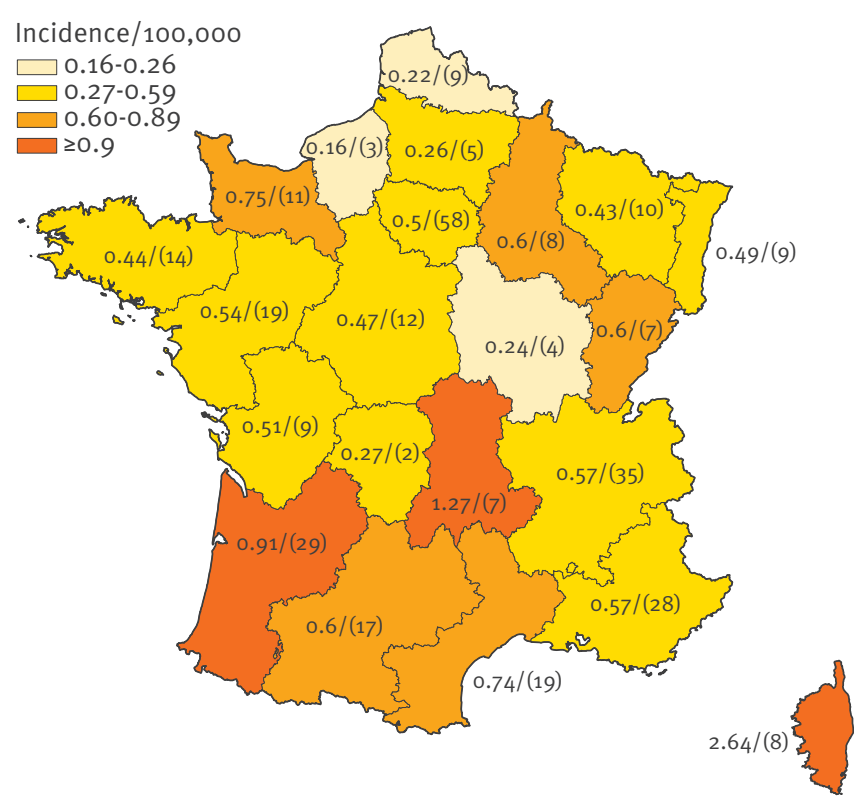

other supermarket chains including chain B and others used by the cases.

As of 15 December, the producer's own checks on raw materials and final products as well as food inspection done during the outbreak investigation of 43 samples (25 $\mathrm{g}$ per sausage per lot) of dried pork sausages produced between 24 August and 21 November resulted negative for Salmonella.

The sausages had been distributed nationwide in metropolitan France, the French department of La Reunion, the French overseas territories of Saint Pierre and Miquelon and French Polynesia, and also in Maurice Island. In addition, there was secondary distribution by supermarket chain A to Poland, Portugal and Slovenia.

\section{Discussion}

We describe a nationwide outbreak of salmonellosis involving 337 identified cases of infection with the Salmonella enterica serotype 4,[5],12:i:- between 31 October and 18 December 2011. The investigation indicated dried pork sausage from producer $\mathrm{X}$ as being the most likely source of the outbreak.

The incrimination of the dried sausage was supported by the following findings: Firstly, an unusually high proportion of the interviewed cases reported having eaten dried sausage. Secondly, the proportion of cases that had bought pork delicatessen in supermarket chain $A$ was much higher than the market share of this supermarket chain among the different supermarket chains in France. Thirdly, according to loyalty card records from supermarket chain A, around $68 \%$ of the cases' purchases of sausages were sausages from producer X. However producer X's sausages represent less than $3 \%$ of the sausages market share at supermarket chain A. This discrepancy makes it likely that the vehicle of infection was dried pork sausage from producer $X$. Finally, the fact that more than half of the production of producer $X$ is sold through supermarket chain $A$ explains the high proportion of cases that purchased dried pork sausage at supermarket chain A.

Public health measures were implemented on 16 December 2011: The DGAL ordered a withdrawal and a recall with a press release and posters, which applied to all supermarkets distributing the incriminated sausage. As accurate identification of suspect lots was not possible, the withdrawal/recall applied to all lots put on the market between 1 October and 15 December, considering the three months of shelf life of the product. To be released on the market, newly produced lots had to pass a reinforced sampling plan and a clearance monitoring. Countries that received those sausages from producer $X$ or via the supermarket chains were informed on 20 and 23 December through the Rapid Alert System for Food and Feed (RASFF).

The use of the loyalty card from supermarket chain A was important to identify the vehicle of infection and 
the local producer involved in this outbreak. These cards are used more and more and prove helpful in the investigation of food-related outbreaks. Nevertheless we should keep in mind that they do not necessarily reflect the consumption of cases perfectly. For instance, the card may not be used systematically, the household can purchase foods in additional shops and markets for which they have no loyalty cards, many food products are consumed outside the household and not recorded on the card, and the central database of the supermarket does not always contain data on all foods sold such as foods directly purchased by the retailers. For these reasons the data have to be interpreted together with the results from epidemiological and microbiological investigations.

That the producer and microbiological analysis did not find Salmonella does not exclude contamination. The limited number of samples and the processing of the food (especially salting and drying) reduce the likelihood of isolating the bacteria. Implementing checks earlier in the process (before salting and drying) and using additional methods of testing such as polymerase chain reaction (PCR) should be considered.

The outbreak strain was the most common genotype of Salmonella enterica serotype 4,[5],12:i:-. The low diversity of genotypes among this serotype did not allow a more specific case definition with the techniques used.

In this investigation we focused efforts on descriptive epidemiology and detailed trace-back data from loyalty cards. A case control study was not performed because such a study may have shown an association with sausage, but would not have contributed to the identification of the brand name necessary to take control measures.

\section{Conclusion}

Considering the epidemiological investigation and trace back results suggesting a link between Salmonella enterica 4,[5],12:i:- infection and consumption of dried pork sausages from producer $X$, and despite the absence of positive sampling results on the sausages, control measures including withdrawal/recall were implemented. The epidemic peak has passed and the number of cases has been at the usual level since week 522011.

Monophasic Salmonella enterica variants are becoming predominant in the European Union [2,4-7 and personal communication, European Centre for Disease prevention and Control, 17 Jan 2011] and are increasingly reported in humans, animals and food samples. This is the second described outbreak in France involving dried pork sausage, and indicates that this food item might be a likely vehicle of infection and further outbreaks in humans may be expected [12].

Given the limitations to detect Salmonella in dried sausages, the ability of the standard reference method to detect of monophasic variant strains in dried sausages is questionable. Additional methods should be explored in order to improve monitoring protocols.

\section{Acknowledgments}

Special thanks to all the persons of the unit Enteric, Foodborne and Zoonotic infections, the HIV/AIDS-STI-HCVHBV unit, Cire Aquitaine, Sandrine Daniel and Delphine Sauvageot for their assistance in the investigation of this outbreak.

* Erratum: The name of V Vaillant was erroneously left out of the list of authors at the time of publication of this article. This mistake was corrected on 3 February 2012. We apologise to the authors.

\section{References}

1. EFSA Panel on Biological Hazards (BIOHAZ). Scientific Opinion on monitoring and assessment of the public health risk of "Salmonella Typhimurium-like" strains. EFSA Journal. 2010;8(10):1826. doi:102903/jefsa20101826. Available from: http://www.efsa.europa.eu/en/efsajournal/pub/1826.htm

2. Hopkins KL, Kirchner M, Guerra B, Granier SA, Lucarelli C, Porrero MC, et al. Multiresistant Salmonella enterica serovar 4,[5],12:i:- in Europe: a new pandemic strain? Euro Surveill. 2010;15(22):pii=19580. Available from: http://www. eurosurveillance.org/ViewArticle.aspx?Articleld=19580

3. Bugarel M, Granier SA, Bonin E, Vignaud ML, Roussel S, Fach $P$, et al. Genetic diversity in monophasic $(1,4,[5], 12: \mathrm{i}:-$ and $1,4,[5], 12:-: 1,2)$ and in non-motile $(1,4,[5], 12:-:-)$ variants of Salmonella enterica S. Typhimurium. Food Research International. 2011. doi:10.1016/j.foodres.2011.06.057

4. Dionisi AM, Graziani C, Lucarelli C, Filetici E, Villa L, Owczarek $\mathrm{S}$, et al. Molecular characterization of multidrug-resistant strains of Salmonella enterica serotype Typhimurium and Monophasic variant (S. 4,[5],12:i:-) isolated from human infections in Italy. Foodborne Pathog Dis. 2009;6(6):711-7.

5. Echeita MA, Herrera S, Usera MA. Atypical, fljB-negative Salmonella enterica subsp. enterica strain of serovar $4,5,12: \mathrm{i}$ : appears to be a monophasic variant of serovar Typhimurium. Clin Microbiol. 2001;39(8):2981-3.

6. Mossong J, Marques P, Ragimbeau C, Huberty-Krau P, Losch $\mathrm{S}$, Meyer G, et al. Outbreaks of monophasic Salmonella enterica serovar 4,[5],12:i:- in Luxembourg, 2006. Euro Surveill. 2007;12(6):pii=719. Available from: http://www. eurosurveillance.org/ViewArticle.aspx?Articleld=719

7. Switt Al, Soyer Y, Warnick LD, Wiedmann M. Emergence, distribution, and molecular and phenotypic characteristics of Salmonella enterica serotype 4,5,12:i. Foodborne Pathog Dis. 2009;6(4):407-15.

8. Gallay A, Bousquet V, Siret V, Prouzet-Mauleon V, Valk $\mathrm{H}$, Vaillant $\mathrm{V}$, et al. Risk factors for acquiring sporadic Campylobacter infection in France: results from a national case-control study. J Infect Dis. 2008;197(10):1477-84.

9. Hunter SB, Vauterin P, Lambert-Fair MA, Van Duyne MS, Kubota K, Graves L, et al. Establishment of a universal size standard strain for use with the PulseNet standardized pulsed-field gel electrophoresis protocols: converting the national databases to the new size standard. J Clin Microbiol. 2005;43(3):1045-50.

10. Larsson JT, Torpdahl M, Petersen RF, Sorensen G, Lindstedt BA, Nielsen EM. Development of a new nomenclature for Salmonella typhimurium multilocus variable number of tandem repeats analysis (MLVA). Euro Surveill. 2009;14(15): pii=19174. Available from: http://www.eurosurveillance.org/ViewArticle. aspx?Articleld $=19174$

11. Wattiau P, Boland C, Bertrand S. Methodologies for Salmonella enterica subsp. enterica subtyping: gold standards and alternatives. Appl Environ Microbiol. 2011;77(22):7877-85.

12. Bone A, Noel H, Le Hello S, Pihier N, Danan C, Raguenaud ME, et al. Nationwide outbreak of Salmonella enterica serotype 4,12:i:- infections in France, linked to dried pork sausage, March-May 2010. Euro Surveill. 2010;15(24):pii=19592. Available from: http://www.eurosurveillance.org/ViewArticle. aspx?Articleld $=19592$ 